Revista lus et Praxis, Año 26, № 1, 2020, pp. 124 - 148

ISSN $0717-2877$

Universidad de Talca - Facultad de Ciencias Jurídicas y Sociales

Justicia transicional: en la posmodernidad del derecho

Carlos Felipe Rúa Delgado

Trabajo recibido el 1 de octubre de 2018 y aprobado el 15 de octubre de 2019

\title{
Justicia transicional: en la posmodernidad del derecho
}

TRANSITIONAL JUSTICE: IN THE POSTMODERNITY OF THE LAW

CARLOS Felipe Rúa DELGADO*

RESUMEN

El texto plantea la cuestión de si la justicia transicional, como paradigma contemporáneo en materia de resolución de conflictos, responde a una herencia de la posmodernidad, a partir de la ruptura del derecho positivo como metarrelato de la modernidad. Para ello se parte de la configuración del metarrelato del derecho positivo, la explicación del proceso de ruptura consistente en la posmodernidad, la redefinición del derecho posmoderno como nuevo metarrelato y la correspondencia de ese nuevo metarrelato con la justicia transicional.

ABSTRACT

This text is about transitional justice as contemporary paradigm in conflict resolution. It responds to a legacy of postmodernity, starting with the rupture of the positive law as metanarrative about modernity. The analysis starts with the positive law as metanarrative, after there is an explanation about the process of rupture of modernity by the postmodernity, and redefinition of the postmodern law as a new metanarrative and the correspondence of this new metanarrative with transitional justice.

PALABRAS CLAVE

Modernidad, posmodernidad, metarrelato, derecho positivo, justicia transicional.

KEY WORDS

Modernity, postmodernity, metanarrative, positive law, transitional justice.

\section{Introducción}

La justicia transicional se ha convertido en la lengua común para la resolución de los conflictos armados en las últimas décadas. Casos como los de Suráfrica, Timor Oriental o Irlanda del Norte sirven de ejemplo para ello. La preocupación por un modelo de justicia que permitiera, tanto la lucha contra la impunidad como la preservación del orden jurídico, constituyó uno de los logros más importantes para el derecho internacional de los últimos años, en tanto que de esta manera se superaba la contradicción que se manifestaba en los tribunales ex post facto, los cuales ponderaban la lucha contra la impunidad por sobre los principios de legalidad y de juez natural. Efectivamente, la justicia transicional utiliza al Derecho como el vehículo que permite la superación de un conflicto, a través de normas que incorporan estándares internacionales definidos en materia de verdad, justicia, reparación y garantías de no repetición; normas que deben constituir un marco jurídico para la transición esperada. Ahora bien, como cada conflicto goza de sus particularidades ${ }^{1}$, la justicia

\footnotetext{
${ }^{*}$ Abogado, Universidad Santiago de Cali, Colombia y Magíster en Educación Superior de la misma universidad. Doctorando en Ciencias Sociales y Jurídicas, Universidad Rey Juan Carlos, Madrid, España. Profesor de tiempo completo e investigador de la Universidad de San Buenaventura, Cali, Colombia. Líder del Grupo de Investigación Problemas Contemporáneos del Derecho y la Política (Gipcodep) de la Universidad de San Buenaventura, Cali, categoría A en Colciencias. Correo: cfrua@usbcali.edu.co. Orcid: 0000-0002-8915-8968

${ }^{1}$ Ver: DEL RíO (2014), p. 1170.
} 
transicional entraña, en su interior, que lo normativo está compuesto por dos referentes necesarios: uno jurídico, que se refiere a la incorporación de los estándares internacionales en derechos humanos, y uno político, que supone los elementos propios y necesarios para la transición ${ }^{2}$.

La incorporación directa de un referente político en la norma jurídica de justicia transicional, implica superar la pureza del Derecho proclamada por el iuspositivismo kelseniano, lo que a su vez configura una manifestación del posmodernismo jurídico, bien sea por la crisis del derecho positivo como metarrelato de la modernidad, o bien por la estructuración de un nuevo metarrelato jurídico. Un metarrelato se entiende como "una gran narración con pretensiones justificatorias y explicativas de ciertas instituciones o creencias compartidas" 3 .

La inclusión de la justicia en el Derecho derivó en la aparición de los derechos humanos, los cuales fueron adoptados como normas de ius cogens, dado el carácter moral que subyace en estos, lo que permite que se ubiquen en la "encrucijada de lo moral y de lo jurídico"4.

Los influjos de la posmodernidad en el derecho, lejos de tratarse de una "pasajera extravagancia", en paráfrasis a Kaufmann, expresan ahí "algo esencial en la conciencia de nuestra época" 5 . Ese algo al que se refiere Kaufmann, parte del nuevo imperativo categórico pensado por Adorno consistente en la búsqueda permanente de una no repetición de Auschwitz ${ }^{6}$. Los horrores del Tercer Reich, encontraron su cimiente en el derecho positivo alemán ${ }^{7}$, razón por la cual la justificación de lucha contra la impunidad que determinó los juicios de Núremberg, no se encontró en el derecho positivo, sino en un derecho natural materializado en derechos humanos ${ }^{8}$.

Al sentir de Kaufmann ${ }^{9}$, aun cuando el renacimiento del derecho natural en el siglo XX obedeció al episodio concreto de la segunda guerra mundial, sus consecuencias, imprevisibles para ese entonces, determinaron una reconfiguración del derecho, en donde contenidos de justicia y de política procuraron incorporarse a la norma jurídica, generando múltiples rupturas con el iuspositivismo dominante, lo que acarreó, entre otras consecuencias, que medio siglo después de Auschwitz se hablara de la justicia transicional como fórmula jurídica de resolución de conflictos.

\section{El derecho positivo como expresión de la modernidad}

La modernidad corresponde tanto a un proyecto como a un proceso, a una época y a un discurso ${ }^{10}$. Entendida como una época, la modernidad se suele ubicar entre el siglo XVII en adelante, de donde surgieron patrones de generalización que se extendieron a escala global, principalmente hacia occidente ${ }^{11}$. La modernidad nace de la llustración y se caracteriza por el espíritu de la razón que impregna con su fuerza todas las esferas de la vida, de donde se desprende un optimismo basado en la razón que determinan la organización racional de la vida, lo cual se presenta sobre los

\footnotetext{
${ }^{2}$ Ver: RÚA (2015), pp. 78-79.

${ }^{3}$ DIÉGUEZ (2004).

${ }^{4}$ PAPACCHINI (2003), p. 50.

${ }^{5}$ KAUFMANN (2014), p. 14.

6 "Hitler ha impuesto a los hombres en estado de no-libertad un nuevo imperativo categórico: orientar su pensamiento y su acción de tal modo que Auschwitz no se repita, que no ocurra nada parecido". ADORNO (2005), p. 334.

7 Ver: RADBRUCH (2009), pp. 25-41.

8 Ver: PAPACCHINI (2003) p. 51.

${ }^{9}$ KAUFMANN (2014) pp. 13-14.

10 "La modernidad desde una perspectiva cultural es una compleja estructura de valores, conocimientos, comportamientos, contextos culturales y fenómenos sociales". TREVIÑO (2006), p. 9.

${ }^{11}$ Ver: GIDDENS (1993), pp. 15-16.
} 
avances de la ciencia, enmarcados en un proceso de libertad y secularización ${ }^{12}$. Para Kant ${ }^{13}$ la Ilustración implica la mayoría de edad del hombre, lo que se ve representado en el entronamiento de la razón, que le permite el hombre servirse a sí mismo, sin la dirección de otro.

Las características de la modernidad pueden sintetizarse de esta manera: a) el triunfo de los intereses laicos sobre los religiosos; b) aparición del derecho, los Estados nacionales y los aparatos de la administración pública modernos; c) el surgimiento de una ética política laica y mundana; d) el pensar al hombre como sujeto de la historia; e) el desarrollo de las ciencias naturales y el interés científico en conocer al mundo; f) un arte que privilegia lo real por sobre lo simbólico ${ }^{14}$.

El ascenso de la razón implicó una ruptura con las explicaciones esotérica y divina del mundo y de la naturaleza, por eso la modernidad, como proyecto, apareja diversos procesos derivados de una visión estrictamente racional, por ejemplo, la fundamentación científica de la explicación de la naturaleza, lo cual acarrea propósitos universales ${ }^{15}$. La naturaleza pasa de ser considerada como creatura de la creación, énfasis propuesto por la escolástica medieval, por la cual solo es posible su comprensión a la luz de la gracia del creador $^{16}$, a ser el objeto de estudio al cual es posible acceder a través, no solo de los sentidos y la experiencia sensible, sino también de la investigación científica, de la experimentación, de la racionalidad ${ }^{17}$.

La secularización del mundo, con el consecuente ascenso de la racionalidad como explicación de este, implican la asunción del destino de la historia por el hombre, no como simple

12 Ver: MARGOT (2008), pp. 141-142.
${ }^{13}$ KANT (1994), p. 7.
${ }^{14}$ Ver: RÚA (2013), p. 27.
${ }^{15}$ Ver: HABERMAS (2008), p. 28.
16 “La misión del pensamiento medieval consistió sobre todo en copiar la arquitectónica del ser, escribiéndola en claras li neas

16 "La misión del pensamiento medieval consistió sobre todo en copiar la arquitectónica del ser, escribiéndola en claras li neas
fundamentales. En el sistema religioso de la Edad Media, como lo formuló la escolástica, cada realidad tiene su lugar fijo e inconfundible y, con este lugar, con la distancia mayor o menor a que se halla del ser de la causa suprema, se determina también su valor. Ni puede ni debe haber aquí duda alguna, y todo pensamiento se siente protegido en un orden inviolable que no es menester crear, sino tan sólo dejarse impresionar por él. Dios, el alma, el mundo, constituyen los tres grandes goznes del ser y con arreglo a ellos se articula el sistema del saber. En modo alguno se elimina en este sistema el conocimiento de la naturaleza; pero desde el principio se halla inscrito en un círculo "rígido del ser, que no puede sobrepasar si no quiere perderse, si no quiere que la luz que en él opera se cambie en tiniebla. El conocimiento coincide con el conocimiento de las criaturas y es un saber en la medida en que es accesible a un ser finito creado y dependiente, un saber que no se extiende sino a los objetos sensibles y finitos. Así, lo mismo por el lado del sujeto como por el objeto, se halla limitado y vinculado. Es verdad que en el pensamiento medieval no coinciden las fronteras del conocimiento natural con las de la existencia material, de lo físico-corpóreo. No sólo existe un conocimiento natural del mundo de los cuerpos y de las fuerzas que actúan en él, sino también un conocimiento natural del derecho, del estado, de la religión y de sus verdades fundamentales. Porque el ámbito del conocimiento natural no se determina a partir del objeto, sino por su origen. Todo saber, cualquiera que sea su contenido, es natural cuando procede únicamente de la razón humana y, sin apoyarse en ninguna otra fuente ele certeza, se basa en sí mismo. Naturaleza significa, por lo tanto, no ya un círculo de objetos, sino un determinado horizonte del saber, del abarcar la realidad. Le corresponde todo lo que cae dentro del campo de visión de la lumen naturale y no requiere para su legitimación y entendimiento ninguna otra ayuda que las fuerzas natura les del conocimiento. En este sentido el reino ele la naturaleza se opone al reino de la gracia. El primero se nos comunica mediante la percepción sensible y el proceso, que se enlaza con ella, del juicio y secuencia lógicos, del uso discursivo del entendimiento; el segundo no nos es accesible más que en virtud de la revelación. No es menester que haya una oposición entre el creer y el saber, entre la revelación y la razón. Los grandes sistemas de la escolástica más bien consideran como su tarea principal el conciliar est os dos mundos y armonizados de sus contenidos. El reino de la gracia no cancela el reino de la naturaleza. Si se eleva por encima de la naturaleza no por eso la afecta en su constitución pura: gratia naturam non tollit sed perficít". CASSIRER (1993), pp. 56-57.

17 "Junto a la verdad de la revelación se presenta ahora una verdad de la naturaleza, autónoma, propia y radical. Esta verdad no se nos ofrece en la palabra de Dios, sino en su obra, no descansa en el testimonio de la Escritura o de la tradición, sino que se halla constantemente ante nuestros ojos. Es legible tan sólo para aquel que conozca los rasgos de la escritura que la expresa y sepa descifrarlos. No es posible revestirla de puras palabras, pues la expresión correspondiente y adecuada es la de las formas matemáticas, las figuras y los números; pero, con éstos, se nos presenta en forma perfecta, sin solución de continuidad y en transparente claridad. La revelación nunca llega por la palabra a esta claridad y transparencia, a esta univocidad; porque la palabra, como tal, es siempre multívoca y oscilante, y permite una multiplicación de interpretaciones. Su comprensión e interpretación es obra humana y, por lo tanto, fragmentaria, mientras que en la naturaleza tenemos ante nosotros en textura infragmentada e infragmentable el plan según el cual ha sido construido el universo, y que no parece esperar sino al espíritu humano para que lo conozca y lo, exprese”. CASSIRER (1993), p. 60. 
pasajero o espectador, sino como sujeto de esta, deja de ser un títere de fuerzas mágicas para convertirse en el "timonel de su propio barco"18.

La ciencia como concreción de la razón, implica una nueva relación con el sujeto, a partir de leyes generales que permiten extrapolaciones y deducciones, en el marco de un ejercicio de comprensión del entorno de forma racional ${ }^{19}$. La subjetividad adquiere, en la modernidad, la nueva forma de relación con el mundo, una realidad verdadera derivada de la racionalización del mundo, en donde el sujeto se siente parte del mundo y sujeto en donde se origina la verdad, es decir, en la modernidad el hombre asume el rol de origen de la verdad, entendiendo por esta la que se origina en el acto de conocimiento, en la experiencia, y no solo un destinatario de la misma, asumiendo el origen de la verdad por fuera del hombre ${ }^{20}$; por ello la subjetividad moderna implica el paso de una "experiencia vivida del mundo a una ciencia observada de la materia donde se constituye la conciencia del individuo moderno" 21 . En este punto resulta fundamental el cogito cartesiano, en tanto que, a través de la duda sistemática, se da origen a un método general por el que se pretende acceder al conocimiento del mundo a través de la razón, pilar fundamental de la modernidad, en tanto que la fe cede ante la razón como condición fundamental para el conocimiento ${ }^{22}$.

La modernidad aparece entonces como una condición de la historia ${ }^{23}$, en tanto que sus metarrelatos, corresponderán a los metarrelatos de la historia; así el derecho positivo, la configuración del Estado, el modo de producción capitalista, el individualismo de corte liberal, la secularización del mundo y el entronamiento de la razón, adquirirán una clave justificatoria de la historia misma. Luego entonces, el derecho positivo, en cuanto metarrelato de la modernidad, primero debe romper con la tradición que lo vinculaba con la voluntad divina, para de ahí desprender un derecho natural derivado de la racionalidad. Racionalidad e individualidad serán las parteras del derecho, en tanto que ahí aparecen los conceptos fundamentales del mismo. El sujeto racional es quien reflexiona sobre sus libertades, no como concesiones, sino como atribuciones derivadas de su humanidad en un mundo secularizado ${ }^{24}$. Este fenómeno va aparejado con el abandono de la metafísica por el auge de las ciencias experimentales.

El derecho, al adoptar para sí los patrones de la modernidad, se constituye en fuente de organización social y política, al punto de que no puede hablarse de modernidad sin derecho moderno ${ }^{25}$. En la modernidad, el derecho transmutó de un derecho natural basado en la voluntad

\footnotetext{
${ }^{18}$ CRUZ KRONFLY (2007) p. 37.

${ }^{19}$ Ver: HABERMAS (1993) p. 30.

20 "Realidad derivada y verdad derivada, mundo escindido y pensamiento de la separación, re-presentación de un mundo extraño y angustiante, imperiosa necesidad de evidencia que le garantiza al hombre una seguridad ontológica, la de ser parte de del mundo $-\mathrm{y}$ no solamente de participar del mundo - todo ello merece el calificativo de subjetividad moderna, en tanto que a partir del momento en que el hombre deja de identificar la realidad verdadera del mundo, es decir, la verdad del mundo, con la experiencia inmediata que hace del mundo, es decir, la verdad del hombre, el hombre pasa a ser destinatario de la verdad a ser el sujeto desde donde la verdad se origina". MARGOT (2004), p. 15.

${ }^{21}$ Ver: MARGOT (2004), p. 16.

22 "Era el primero, no aceptar nunca cosa alguna como verdadera que no la conociese evidentemente como tal, es decir, evitar cuidadosamente la precipitación y la prevención y no admitir en mis juicios nada más que lo que se presentase a mi espíritu tan clara y distintamente, que no tuviese ocasión de ponerlo en duda". DESCARTES (1975), p. 55.

${ }^{23}$ Ver: CASULLO (2009), p. 10.

${ }^{24}$ Ver: LÓPEZ (1997), p. 11.

${ }^{25} \mathrm{El}$ derecho aparece "como un potente motor de racionalización de la organización social y política, por lo cual se reviste de los atributos de objetividad y de necesidad. El derecho es, pues, al mismo tiempo, la expresión y el vector de la modernidad". CHEVALIER (2011), p. 173.
} 
divina a un derecho natural que se desprende del racionalismo, para finalmente aterrizar en un derecho positivo que tendrá en la ley ${ }^{26}$ a su máxima expresión ${ }^{27}$.

La justificación de la teoría pura kelseniana, implica el tránsito del iusnaturalismo racionalista al positivismo, proceso que va de la mano con el ascenso de la democracia en desmedro del absolutismo monárquico, lo que va a generar el efecto simbólico de la ley como producto superior de la soberanía popular, por provenir del órgano de deliberación democrática por excelencia, como lo es el legislador ${ }^{28}$. Esta justificación ya aparece en Rousseau, para quien las leyes no son cosa distinta a las condiciones de la asociación civil, sobre el principio de la voluntad genera ${ }^{29}$, justificación que va a servir de entronque teórico a la teoría kelseniana.

El derecho positivo, como hijo de la modernidad, ha planteado fuertes críticas al iusnaturalismo ${ }^{30}$, las cuales permitieron el proceso de consolidación del derecho positivo como metarrelato de la misma modernidad. Autores como Kelsen ${ }^{31}$ señalan que las profundas contradicciones emanadas de un naturalismo que no detenta un asidero científico sólido, terminan entrañando profundas contradicciones, al punto que desde el iunaturalismo se pueden justificar tanto la democracia como el absolutismo, tanto el comunismo como el capitalismo. Por ello este autor concluye que "con un método fundado en un sofisma, como lo es la teoría del derecho natural, se puede demostrar todo, o, lo que es lo mismo, no es posible demostrar nada" 32 .

Ello conlleva a una separación entre el derecho y la justicia, en donde la justicia, si bien se considera como un producto de la moralidad, la subjetividad determinante en los contenidos de lo que es justo, hacen que un orden jurídico no pueda ser considerado justo o injusto, por ello la pureza del derecho proclamada por Kelsen ${ }^{33}$ como epítome del devenir positivista, termina por considerar que los contenidos de la justicia no pueden ser definidos como un absoluto, lo que resta carácter científico a la ciencia del derecho y por ello se justifica su separación conceptual.

Consecuencia directa de la separación entre la justicia y el derecho, es que la validez de las normas positivas se predica a partir de su mera existencia, más no de sus contenidos, es decir, una norma será válida solo si ha sido producida como lo define el mismo derecho, siguiendo las reglas determinadas para la producción normativa ${ }^{34}$, más no por los fines que esta persiga.

La desvinculación de la justicia al derecho positivo, termina generando una confusión en torno a los contenidos de la justicia, al punto de que si se trata a la justicia como un valor absoluto, al estar el positivismo vinculado con el relativismo, la pregunta por la justicia deja de ser absoluta para relativizarse, al punto de que puede aparejarse lo jurídico a lo justo ${ }^{35}$. El derecho positivo se constituye en metarrelato de la modernidad en la medida en que trata de dotar de carácter científico al derecho, como una ciencia que depende de sí misma, al descartar todo juicio ético o político, asumiendo un carácter objetivista ${ }^{36}$. La racionalidad de la modernidad encuentra su epítome jurídica en el positivismo, principalmente en el de corte kelseniano, dado que

\footnotetext{
${ }^{26}$ Según Cassirer: "el concepto perfecto de la ley presupone sin duda un mandamiento dirigido a la voluntad individual. Este mandamiento no crea la idea del derecho y de la justicia, sino que se subordina a ella, la pone en ejecución actual”. CASSIRER (1993), pp. 267-268.

${ }^{27}$ Ver: BERNAL (2010), p. 162.

${ }^{28}$ Ver: KELSEN (2009), p. 53.

${ }^{29}$ ROUSSEAU (2003), pp. 68-71.

${ }^{30}$ Ver: SERNA (1989), p. 160.

${ }^{31}$ Ver: KELSEN (2005), p. 72.

32 KELSEN (2005), p. 73.

${ }^{33}$ KELSEN (2009), p. 48.

${ }^{34}$ Ver: KELSEN (2009), p. 31.

${ }^{35}$ Kelsen explica al respecto: "Todo derecho positivo puede ser considerado como relativamente justo en tanto orden de la conducta humana. Esto significa, sin embargo, que el juicio que afirma que un orden jurídico es relativamente justo conduce a la tautología de que este orden jurídico es derecho". KELSEN (2007), pp. 31-32.

${ }^{36}$ Ver: BOTERO (2014), pp. 13-20.
} 
logra consolidar el valor científico del derecho, ya no como ideología, o discurso, o práctica ideologizada, sino como una ciencia social. Racionalidad e individualidad se erigen en pilares estructurales de la ciencia jurídica que predica su pureza a partir de la identidad de epistemológica de sus elementos ${ }^{37}$.

\section{La posmodernidad o la crisis de los metarrelatos}

La crisis de los metarrelatos de la modernidad es lo que se ha dado en llamar posmodernidad. Para Lyotard "se tiene por "postmoderna" la incredulidad con respecto a los metarrelatos" ${ }^{38}$. Así como la modernidad significó una ruptura con el pasado, con lo divino, con lo feudal, con lo no científico, erigiendo para ello sus propios metarrelatos, la posmodernidad también significó un cambio de época, una nueva realidad construida sobre nuevos metarrelatos ${ }^{39}$. Si el subjetivismo, como concreción de la individualidad, responde a una de las notas características más importantes de la modernidad, la crisis del sujeto lo será - a su vez - de la posmodernidad ${ }^{40}$. Para Horkheimer la crisis de la razón encuentra una de sus manifestaciones más visibles en la crisis del individuo, lo que afecta la médula misma del proyecto modernista ${ }^{41}$.

La posmodernidad implica concebir la historia sobre la base de la incertidumbre, el cambio en los paradigmas implica la pérdida de la idea del progreso ${ }^{42}$, en términos de Vattimo la posmodernidad puede asumirse como el fin de la historia ${ }^{43}$. La historia como decurso de representación del pasado implica el apoderarse de este para pensar el futuro en lo que se llama progreso. Para Benjamin "la historia es objeto de una construcción cuyo lugar no es el tiempo homogéneo y vacío, sino el que está lleno de tiempo del ahora" ${ }^{44}$. El progreso, como aspiración de la modernidad, guarda su correspondencia con la visión unitaria de la historia, dado que la crisis de la historia moderna está basada en la idea racional del progreso ${ }^{45}$. Así, la crisis de la historia implica "un consecuente debilitamiento de la historicidad, un vaciar de contenido el futuro, llevando a la indistinción las edades humanas" 46 .

\footnotetext{
37 “La teoría pura del derecho, por el contrario, tiene un carácter objetivista y universalista. Estudia el derecho en su totalidad y sólo se interesa por los fenómenos particulares para establecer una relación sistemática entre cada uno de ellos y para volver a encontrar en ella la función general del derecho. Sustenta una concepción orgánica del derecho, sin que por ello participe de la opinión de los que por razones de orden ético o político ven en el derecho una entidad supraindividual, de naturaleza biológica o psicológica que escaparía a la existencia, y que tendría así un carácter metafísico. Para la Teoría pura la idea de que el derecho es un organismo significa solamente que es un sistema de normas y que todos los problemas jurídicos deben ser considerados y resueltos como los problemas de un orden normativo. Al descartar de este modo todo juicio de valor ético o político, la teoría del derecho se convierte en un análisis lo más exacto posible de la estructura del derecho positivo". KELSEN (2009), p. 107.

38 LYOTARD (1987), p. 4.

${ }^{39}$ La modernidad supone entonces "una ruptura epocal con la modernidad, que conlleva la aparición de una nueva totalidad social con sus propios principios distintos de organización" FEATHERSTONE (2000), p. 24.

${ }^{40}$ Ver: JAMESON (2008), p. 170.

${ }^{41}$ Según Horkheimer "el individuo concebía otrora a la razón exclusivamente como instrumento del yo. Ahora experimenta la inversión de tal autodivinización del yo". HORKHEIMER (1973), p. 138.

${ }^{42}$ Ver: ZERAOUI (2006), p. 32.

${ }^{43}$ Para Vattimo "pensar lo posmoderno como fin de la historia, como el final del fin, no significa, entonces, darse cuenta de que la cuestión hubiera ya dejado de proponerse, sino, al revés, situar en el primer plano de una atención central la cuestión de la historia como raíz de legitimaciones". VATTIMO (1991), p. 20.

${ }^{44}$ BENJAMIN (2013), p. 28.

45 "La crisis de la ideal de la historia lleva consigo la crisis de la idea de progreso: si no hay un decurso unitario de las vicisitudes humanas, no se podrá ni siquiera sostener que avanzan hacia un fin, que realizan un plan racional de mejora, de educación, de emancipación". VATTIMO (1994), pp. 10-11.

${ }^{46}$ CUARTAS (2015), p. 139.
} 
Vale decir, sin embargo, que autores como Habermas consideran a la modernidad como un proyecto inacabado que merece la pena continuar, y más bien aprender de los errores incurridos en nombre de la posmodernidad ${ }^{47}$.

Aun así, la tecnologización de la vida, las relaciones, las ciencias y el humanismo, derivados de la sociedad post industrial, hacen que autores como Lyotard, signifiquen la erosión de la racionalidad, como metarrelato estructural de la modernidad, lo que ha llevado a una deslegitimación de la ciencia a partir del auge de la especulación ${ }^{48}$. En el mismo sentido, Beuchot ${ }^{49}$, al explicar la crisis de los metarrelatos en Lyotard, reconoce el proceso de deslegitimación de los relatos de la ciencia por la falta de autorización de estos. La crisis de los metarrelatos es la crisis de la razón, la crisis de la ciencia, en tanto que la ciencia forma parte del modo de producción, es así como la ciencia dejó de lado su propósito principal de explicar el mundo, para hacer de su leit motiv el simple desempeño de un rol determinado en el proceso de producción ${ }^{50}$.

La mutación en la racionalidad como metarrelato estructural de la modernidad, de racionalidad emancipadora y partera de la libertad, a una racionalidad instrumental, ejercen, en términos de Adorno ${ }^{51}$, una dialéctica negativa, una profunda contradicción que altera los cimientos mismos de la modernidad, del espíritu de la ilustración, de la mayoría de edad de la humanidad. La razón pasa a convertirse entonces, en una razón instrumental, cuyos propósitos son diametralmente diferentes a la emancipación humana a través de la luz del conocimiento; la razón instrumental se pone al servicio de la tecnología con el fin de lograr nuevas formas de enajenación ${ }^{52}$. Las contradicciones de la modernidad llevaron a que la construcción de subjetividad con miras a alcanzar la libertad, como metarrelato estructural del proyecto moderno, desembocaron en la generación de subjetividades a partir de dispositivos de poder, con miras ya no en la búsqueda de la libertad del sujeto, sino de la reproducción de modelos hegemónicos a partir de la tecnociencia, lo que a la postre representó la caída de la racionalidad, lo cual es palpable en las atrocidades cometidas con ocasión de las guerras mundiales, sobre todo en lo que concierne a los campos de concentración. Es por ello por lo que Lyotard considera que la modernidad encuentra su punto de quiebre en Auschwitz, símbolo absoluto del abandono de la razón ${ }^{53}$.

La Alemania de la primera mitad del siglo XX representó, de forma simultánea y paradójica, la cumbre de la modernidad industrial y la victoria de los prejuicios sobre la razón ${ }^{54}$. No en vano Adorno ${ }^{55}$, dibuja a la modernidad perdida entre las sombras de las dictaduras. Las discordancias de la modernidad que llevan a su desencanto, a propósito del fenómeno de las guerras mundiales, entrañan una visión pesimista de la historia, el punto culmen del pensamiento moderno se cifra en

\footnotetext{
47 Ver: HABERMAS (2008), p. 32.

48 "Una ciencia que no ha encontrado su legitimidad no es una ciencia auténtica, desciende al rango más bajo, el de la ideología o el de instrumento del poder, si el discurso que debía legitimarla aparece en sí mismo como referido a un saber precientífico, al mismo título que un «vulgar» relato". LYOTARD (1987), p. 32.

49 "Todo se va ahora a la pragmática del saber narrativo, que es el saber de la postmodernidad. Se ve como pragmática porque ya no toma el saber como conjunto de enunciados denotativos, sino como competencias prácticas". BEUCHOT (2009), pp. 113-114.

50 Ver: HORKHEIMER (2003), p. 21.

${ }^{51}$ Ver: ADORNO (2005).

52 Ver: FORSTER (2009), pp. 145-146.

53 "Mi argumento es que el proyecto moderno (de realización de la universalidad) no ha sido abandonado ni olvidado, sino destruido, "liquidado". Hay muchos modos de destrucción y muchos nombres le sirven como símbolo de ello, "Auschwitz" puede ser tomado como un nombre paradigmático para la "no realización” trágica de la modernidad”. LYOTARD (1994), p. 30.

${ }^{54}$ Ver: RÚA (2016), pp. 475-476.

55 "En el espanto de las dictaduras regresivas, la modernidad, imagen dialéctica del progreso, se ha consumado en una explosión". ADORNO (2001), p. 240
} 
el siglo XX, precisamente el siglo de Auschwitz y lo que ello representa ${ }^{56}$. Así las cosas, la realidad vivida en el siglo XX significó la aniquilación de la modernidad por sí misma, a través del aparato construido por esta para su reproducción ${ }^{57}$.

Para autores como Horkheimer y Adorno, las contradicciones de la llustración como partera de la modernidad, desencadenaron su propia autodestrucción, a partir de una excesiva confianza en la tecnologización de la ciencia, lo que llevó a que "el pensamiento ciegamente pragmatizado pierde su carácter superador, y por tanto también su relación con la verdad" ${ }^{58}$. Las paradojas de la modernidad, devienen de su concepción como sistema de poder orientada a la apropiación del control $^{59}$, en tanto que la idea de progreso termina generando un sistema de poder regulatorio de las relaciones sociales ${ }^{60}$. Este sistema de poder deviene necesariamente de la racionalidad instrumental que entraña la modernidad, lo que a la postre hace que prácticas como el Holocausto ${ }^{61}$ resultasen razonables, al decir de Bauman ${ }^{62}$.

\section{La justicia como bisagra: la erosión del derecho positivo como metarrelato}

La crisis de los metarrelatos de la modernidad también afectó gravemente al mundo del derecho, no en vano el derecho positivo se erigió en uno de los metarrelatos de la modernidad tardía. Uno de los elementos estructurales del positivismo jurídico corresponde a la distinción de la justicia del Derecho. Para los iusnaturalistas racionalistas como Bentham o Locke, la justicia corresponde a uno de los propósitos principales del derecho, en tanto que lo justo deviene de la naturaleza, es decir, de la naturaleza del hombre dotado de razón. Sin embargo, con el paso hacia el positivismo jurídico, la separación entre la justicia y el Derecho se fue haciendo más evidente, en tanto que la justicia fue incorporada como uno de los contenidos propios del iusnaturalismo, lo cual fue objeto de la crítica devastadora por el positivismo jurídico, verbigracia Kelsen ${ }^{63}$. Para Radbruch ${ }^{64}$,

\footnotetext{
${ }^{56}$ Sofsky lo sentencia en forma de pérdida de esperanza: "El sueño de la victoria de la razón se lo ha llevado el viento. Ahora como antes el mundo está lleno de violencia". SOFSKY (2004), p. 58.

57 "En efecto, el siglo XX - con sus campos de concentración, escuadrones de la muerte, militarismo, dos guerras mundiales, amenaza de exterminio nuclear y la experiencia de Hiroshima y Nagasaki- han aniquilado este optimismo. Peor aún, existe la sospecha de que el proyecto de la llustración estaba condenado a volverse contra sí mismo, transformando así la lucha por la emancipación del hombre en un sistema de opresión universal en nombre de la liberación de la humanidad". HARVEY (2012), p. 28.

${ }^{58}$ Ver: HORKHEIMER Y ADORNO (1998), p. 53.

59 “En el plano del análisis teórico político, se pueden ubicar tres ejes básicos de contradicciones del sistema de poder de la modernidad en el momento inmediatamente posterior a su construcción como sistema de poder hegemónico. Y estos ejes se convierten en contradicciones porque son transformaciones estructurales del sistema de representación del mundo ( $\mathrm{y}$, por lo tanto, también de sí mismo) que, funcionales para producir determinados efectos en el momento de transición a la modernidad, generan efectos inesperados (o cuanto menos disfuncionales) a la propia lógica del poder una vez que ésta se consolida.

De allí su carácter contradictorio: surgen para resolver un problema determinado con la nueva tecnología de poder, pero, en su proceso de consolidación, generan un nuevo problema (de carácter distinto, novedoso) para dicha tecnología. La contradicción se produce en el punto en que el discurso explícito de este sistema de poder entra en conflicto con sus prácticas histórico concretas. Es así como comienza a legitimarse políticamente por medio de un análisis de la realidad que, sin embargo, no practica, lo cual acarrea problemas a nivel de legitimidad, del consenso y de la racionalidad del propio sistema". FEIERSTEIN (2008), p. 113.

60 "Vamos a entender aquí, sin embargo, al concepto de modernidad en su sentido de sistema de poder: de un conjunto de tecnologías específicas (y situadas en el tiempo y en el espacio) de destrucción y reconstrucción de relaciones sociales, pero lo suficie ntemente amplio como para tener diversas (y aun contradictorias) manifestaciones". FEIERSTEIN (2008), p. 111.

61 “La Solución Final señaló el punto en el que el sistema industrial europeo fracasó. En vez de potenciar la vida, que era el anhelo original de la llustración, empezó a consumirse. Esta sistema industrial y la ética asociada a él hicieron que Europa fuera capaz de dominar el mundo". BAUMAN (2011), p. 28.

62 “... el espíritu de la racionalidad instrumental y su institucionalización burocrática no sólo dieron pie a soluciones como las del Holocausto sino que, fundamentalmente, hicieron que dichas soluciones resultaran "razonables", aumentando con ello las probabilidades que se optara por ellas". BAUMAN (2011), p. 39.

${ }^{63}$ Ver: KELSEN (2005).

${ }^{64}$ Ver: RADBRUCH (1980), p. 103.
} 
el bien común, la justicia y la seguridad jurídica constituyen los fines supremos del derecho, sin embargo la relación entre estos tres fines se encuentra delineada por profundas tensiones, enmarcadas en contextos históricos y políticos determinados, lo cual determinará la supremacía de uno $u$ otro ${ }^{65}$. Con la consolidación del positivismo jurídico en las primeras décadas del siglo XX, la tensión entre seguridad jurídica y justicia se hizo más evidente, al punto de que, para efectos de acondicionamiento de la cadena de validez, la justicia erosionó su posición frente a la seguridad jurídica, quien finalmente se acopló como un fin del derecho de mayor relevancia a la justicia ${ }^{66}$.

Las prácticas de los nazis, en la Alemania de la década de 1930, consistentes en la confiscación de bienes y propiedades de judíos, gitanos, comunistas y opositores políticos, así como las prácticas eugenésicas para garantizar la pureza racial, derivaron de mandatos contenidos en leyes positivas, expedidas válidamente de acuerdo con el derecho alemán; en otras palabras, las prácticas iniciales que degeneraron en la shoah y en los horrores presentados en los campos de concentración y exterminio, tuvieron un origen legal en normas válidas de derecho positivo. El positivismo privilegió la seguridad jurídica por sobre la justicia, ponderación que justifica las prácticas de los nazis, legales aunque injustas ${ }^{67}$.

La crítica de Radbruch al positivismo alemán es también la crítica a un sistema de validez basado exclusivamente en las formas de producción normativa con el condigno descuido de los contenidos de la norma, puesto que la búsqueda de la justicia termina siendo relativizada a lo que cada derecho considera justo ${ }^{68}$.

La crisis del derecho positivo como metarrelato de la modernidad se expresa en la necesidad de volver a consentir un maridaje entre el derecho y la justicia, lo que implica superar la pureza del derecho de corte kelseniano ${ }^{69}$.

No quiere ello decir que solo hasta después de la segunda guerra mundial se incorporó la justicia al derecho, sino que, antes de este episodio, y durante el auge del positivismo, la justicia se incorporaba al derecho a partir de una concepción formalista de la misma, es decir, la confusión de los conceptos entre justicia y legalidad, en donde lo justo implica el acatamiento de la ley, siempre y cuando esta sea válida, porque existe una reducción de la justicia a la validez normativa ${ }^{70}$. Ahora bien, una concepción formalista de la justicia, en donde esta se apareja a la legalidad, no quiere decir que los contenidos de justicia estén siendo reivindicados dentro del derecho, por el contrario, es la justicia entendida a partir de la igualdad en el tratamiento jurídico y a la equidad, la que debe incorporarse como fin del Derecho ${ }^{71}$, es decir, una superación de la justicia estrictamente legal que presupone la justicia de las leyes, lo cual desconoce los intereses implícitos en el legislador, que terminan impactando a la ley ${ }^{72}$. Por ello una superación de la justicia eminentemente legal en el derecho, debe permitir superar a la seguridad jurídica en las tensiones que se presenten, en aras de

\footnotetext{
${ }^{65}$ Ver: RADBRUCH (1980), p. 119.

${ }^{66}$ Ver: RADBRUCH (2009), pp. 34-35.

67 “En efecto, el positivismo, con su convicción de que ley es ley, dejó a los juristas alemanes inermes frente a leyes arbitrarias y de contenido criminal. Por ello el positivismo no está en absoluto en condiciones de fundamentar por su propia fuerza la valid ez de las leyes. Cree haber demostrado ya la validez de una ley cuando el legislador tiene el poder de imponerla. Con el poder podrá quizás fundarse una obligación, pero jamás un deber y una validez. Estas se fundan mucho más en un valor inherente a la ley; por supuesto, toda ley positiva lleva un valor en sí misma, independientemente de su contenido: es siempre mejor que la falta de ley, pues crea seguridad jurídica. Pero seguridad jurídica no es el único y decisivo valor que deba realizar el derecho". RADBRUCH (2009), p. 33.

${ }^{68}$ Ver: RADBRUCH (2009), pp. 34-35.

${ }^{69}$ Siguiendo este razonamiento, Atienza concluye que "el jurista no puede resolver ningún problema sirviéndose sólo del Derecho positivo, esto es, sin recurrir a juicios de valor, a juicios sobre lo justo y lo injusto que, por tanto, trascienden el derecho positivo". ATIENZA (2012), p. X.

${ }^{70}$ Ver: BOBBIO (2004), pp. 13-18.

${ }^{71}$ Ver: RADBRUCH (1980), pp. 105-106.

72 Ver: BRIESKORN (1993), p. 111.
} 
precaver una arbitrariedad legal ${ }^{73}$. Es por esta razón que la justicia guarda una relación inescindible con la moral social, entendida como el "conjunto de valores morales vividos en una sociedad, es decir, a la idea de justicia mayoritariamente sentida en un cierto lugar y momento histórico" 74 .

De las tensiones entre bien común, justicia y seguridad jurídica ${ }^{75}$, se estructura una propuesta de justicia que trascienda la concepción puramente formalista ${ }^{76}$, en donde la seguridad sea justa, garantizando para ello la libertad, la igualdad, los derechos fundamentales y las necesidades básicas ${ }^{77}$.

El positivismo de la primera mitad del siglo XX, que es la manifestación más alta de la modernidad en el derecho, frente a la tensión existente entre justicia y seguridad jurídica, optó por la segunda, reduciendo de esta manera la justicia a la validez, en cuanto a que "una norma es justa por ser válida, haciendo depender la justicia de la validez"78, pero dada la situación presentada con las normas emanadas del Tercer Reich, se dieron las rupturas necesarias para volver a incluir a la justicia como fin esencial del derecho, superando incluso a la seguridad jurídica como fin principal, atendiendo no ya a un criterio de justicia estrictamente formalista, sino a un criterio de justicia material, a partir de los conceptos aristotélicos de justicia distributiva y justicia conmutativa. Ello va a servir de guía para el derecho contemporáneo, en donde la ley injusta, aunque formalmente válida, no puede considerarse como Derecho ${ }^{79}$. Siguiendo trazas argumentales similares, Hervada ${ }^{80}$ (señala que la ley injusta carece de juridicidad y en consecuencia, aun cuando tenga apariencia de ley, carece de sustancia de ley. Para el mismo autor ${ }^{81}$, no puede separarse el derecho positivo del derecho natural, dada la relación intrínseca existente entre ambos, partiendo del axioma de que lo cultural -o lo social- parte de lo natural.

Esta imbricación de derecho y justicia se va a concretar en los juicios de Núremberg, en donde los dirigentes nazis fueron juzgados y condenados, a pesar de que muchas de sus prácticas criminales se encontraban amparadas en la ley positiva alemana. Volver a pensar la justicia como componente del Derecho conllevó a pensar en la positivación de unos derechos humanos que emanaban del derecho natural ${ }^{82}$. Véase si no: los jerarcas nazis obraron de conformidad con lo que el ordenamiento positivo les demandaba, sin embargo su actuar fue injusto por cuanto la ley que obedecían era injusta desde sus entrañas; razón por la cual se necesitó del reconocimiento de unos derechos humanos universales y universalizables que permitieran su juzgamiento por parte de los aliados en los juicios de Núremberg, de no ser así, los nazis debieron ser absueltos por cumplir la legislación positiva que como funcionarios del Reich estaban obligados a cumplir, por ello, sin el reconocimiento de los derechos naturales no solo no se habrían podido condenar a los jerarcas nazis en Núremberg, sino que el reconocimiento de unos derechos humanos universales que cobijasen a toda la humanidad, habría sido imposible.

\footnotetext{
73 Ver: RADBRUCH (2009), p. 36.

${ }^{74}$ PRIETO SANCHÍS (2007), p. 96.

75 Ver: RADBRUCH (1980), p. 119.

76 "El principio de igualdad se dirige, predominantemente, a prohibir la arbitrariedad. La justicia material (justicia social), persigue la realización del bien común. La seguridad jurídica pretende la paz jurídica". KAUFMANN (2006), p. 351.

77 Ver: DÍAZ (1998), p. 60.

${ }^{78}$ BOBBIO (1993), p. 40.

79 Ver: VASSALLI (2014), pp. 263-275.

80 HERVADA (2014a), pp. 157-158.

81 "Dado el axioma enunciado, pretender que sólo existe el derecho positivo, esto es, que todo derecho es puesto por el hombre, contradice el más elemental sentido común, pues si hay algo jurídico cultural (positivo), tiene que partir de algo natural". HERVADA (2014b), p. 52

${ }^{82}$ NINO (1989), pp. 14-18.
} 


\section{El derecho en la posmodernidad: coordenadas para un nuevo escenario}

El efecto inmediato de la adopción de un sistema de derechos humanos universal, corresponde a la ruptura del sistema jurídico como un sistema cerrado, en donde el monopolio de la producción normativa está en cabeza del Estado nacional, para dar paso a sistemas abiertos en donde proliferan normas de múltiples fuentes, nacionales e internacionales, incluso normas de soft law que terminan produciendo efectos jurídicos en virtud de las interpretaciones que de ellas hacen las cortes.

Para Chevalier la crisis de la racionalidad jurídica se ve reflejada en que "el derecho perdió los atributos de sistematicidad, generalidad y estabilidad", además de que "la unción estatal y la consagración democrática no bastan ya para certificar la conformidad del derecho a las exigencias de la razón"83. Lo primero se manifiesta claramente en la crisis del sistema de fuentes formales del derecho para dar paso a un pluralismo jurídico que reconoce otras formas de producción normativa distintas al monopolio estatal, lo cual incluye el reconocimiento de principios que vienen de la moral, tal y como acontece, a manera de ejemplo, con el artículo 94 de la Constitución Política de Colombia, en donde expresamente se reconoce la validez de principios que, aun cuando no se encuentran escritos, son inherentes al ser humano y, en consecuencia, se deben considerar como principios constitucionales, con lo que ello representa en términos de supremacía normativa. Lo segundo se evidencia en la adopción de normas internacionales que se integran a los órdenes jurídicos internos sin que medie la voluntad del legislador, muchas veces, debido a que la jurisprudencia ha terminado por suplir tareas del legislativo en la creación del derecho. El tercer punto anotado por Chevalier corresponde a la estabilidad, entendida esta como la ruptura con el monopolio de la producción normativa por parte del Estado, lo que se refleja, por ejemplo, en la incorporación de normas internacionales a figuras como el bloque de constitucionalidad, en donde además de tratados internacionales de derechos humanos, también se suelen incluir normas internacionales de soft law que significan compromisos o interpretaciones en materia de derechos humanos ${ }^{84}$.

Según Ortíz Caballero, el discurso posmoderno que irradia al derecho, implica que

las afirmaciones jurídicas dejan de tener un carácter definitivo o exacto para adoptar una situación de imprecisión o de "solución inacabada" donde las cosas dependen de las particularidades del caso concreto e, inclusive más, pertenecen a la circunstancia actual y no tienen por qué llegar a concreciones exactas ${ }^{85}$.

Como consecuencia, junto con la reformulación de las fuentes del derecho, aparece un escenario difuso en donde la jurisprudencia es la que va a definir la aplicación de los principios jurídicos en cada caso, en donde hace gala de ejercicios argumentativos que no necesariamente se

\footnotetext{
${ }^{83}$ CHEVALIER (2011), pp. 180-182.

${ }^{84}$ Esta serie de rupturas tanto en el carácter sistemático lógico-formal del Derecho, como la integración de sistemas jurídicos internacionales y supranacionales, así como la ruptura en el monopolio estatal de producción normativo, son analizados por Grün: “En efecto, para no citar sino algunos de los más notorios, actualmente se producen varios fenómenos en el ámbito del derecho, en forma simultánea: Por una parte el derecho internacional se transforma rápidamente y asume una función creciente y dominante sobre los sistemas jurídicos nacionales. Los sistemas jurídicos de los diversos Estados se interrelacionan cada vez más entre sí y con sistemas jurídicos internacionales de diversa envergadura, que se orientan rápidamente a constituir un sistema jurídico mundial. De la noción del derecho internacional como un "derecho primitivo", expresado a través de la "comitas gentium" y el principio de "pacta sunt servanda", en pocos decenios se ha pasado a organizaciones complejas y estructuradas como las Naciones Unidas, la Comunidad Europea, la Organización de los Estados Americanos, el Mercosur, etc., estructuras jurídicas que poseen inclusive tribunales con imperium no solamente sobre los Estados Nacionales, con diversa intensidad, sino aún sobre los sujetos de derecho (personas físicas y jur ídicas) de esos Estados". GRÜN (1997), pp. 23-24.

85 ORTíz (2016), p. 16.
} 
basan en los textos normativos, sino en otros textos o discursos que "los validan siquiera referencialmente" 86 .

La jurisprudencia constitucional ${ }^{87}$ ascendió en el sistema de fuentes, de la mano del texto constitucional y en desmedro de la ley ${ }^{88}$, lo que implicó un desplazamiento de la primacía de la ley a la primacía de la Constitución ${ }^{89}$, significando no solo la limitación de la ley misma ${ }^{90}$ y del órgano legislativo, sino la preeminencia de la función judicial ${ }^{91}$, dado que la soberanía popular y sus decisiones tomadas por mayorías se van a encontrar con el freno de mano de la Constitución ${ }^{92}$ y de la interpretación que de esta hace el tribunal constitucional, quien asume su función como legislador negativo, no limitándose a un control formal de validez de las leyes, sino a partir de una revisión de contenidos acordes con el rol de defensor de la Constitución que se le otorga ${ }^{93}$. El control de constitucionalidad de corte kelseniano ${ }^{94}$, que concibe un rol exclusivo de legislador negativo para el tribunal constitucional, a partir de la crisis para el positivismo estricto que representaron los juicios de Núremberg ${ }^{95}$, en donde los jerarcas nazis fueron condenados por cumplir la ley violando el derecho ${ }^{96}$, encontró que el control jurisdiccional de la ley ahora implicaría el control formal y material de la ley desde la Constitución ${ }^{97}$, a partir de los derechos como nuevo parámetro de validez, razón por la cual el defensor de la Constitución debía asumir un papel proactivo en la defensa de los derechos constitucionales, en un contexto en donde las constituciones de postguerra, precisamente, son cada vez más ricas en derechos. Así las cosas, el control de constitucionalidad se

${ }^{86}$ ORTíz (2016), p. 16.

87 “La afirmación de la Constitución como norma jurídica y la consiguiente judicialización del ordenamiento suponen la afirmación de la superioridad jerárquica de la Sentencia del Tribunal Constitucional sobre las demás fuentes del derecho, con la excepción, obviamente, de la propia Constitución y de las leyes de reforma de la misma". PÉREZ (1984), p. 48.

88 "La ley, un tiempo medida exclusiva de todas las cosas en el campo del derecho, cede así el paso a la Constitución y se convierte ella misma en objeto de medición. Es destronada a favor de una instancia más alta. Y esta instancia más alta asume ahora la importantísima función de mantener unidas y en paz sociedades enteras divididas en su interior y concurrenciales. Una función inexistente en otro tiempo, cuando la sociedad política estaba y se presuponía que era en sí misma, unida y pacífica. En la nueva situación, el principio de constitucionalidad es el que debe asegurar la consecución de este objetivo de nulidad". ZAGREBELSKY (1995), p. 40.

89 PÉREZ (2002), p. 61.

90 “(...) la ley suponía entonces el cauce principal y normal de expresión de la voluntad normativa del Estado, de un Estado que consideraba un atributo básico de su soberanía el monopolio del sistema de fuentes jurídicas". PÉREZ (2002), p. 62.

91 “En una interpretación algo simplista y exagerada se ha sostenido que el siglo XIX fue el del legislativo, en el XX predominó el poder administrador y en el XXI se avizora el predominio del judicial". VIGO (2012), p. 27.

92 "Son los jueces - a través de las diversas formas mediante las cuales se puede ejercer el control de constitucionalidad - los que se van a encargar de fiscalizar la actuación del parlamento en relación con la Constitución.

En el Estado Constitucional las aspiraciones de la mayoría parlamentaria, expresión de la soberanía popular, se encuentran con el freno de la Constitución". ANSUÁTEGUI (2011), pp. 35-36.

93 "El control de constitucionalidad de los actuales Tribunales Constitucionales no se reduce a un control meramente formal o procedimental (al modo que propuso Kelsen con su modelo de "legislador negativo"), sino que se comprometen con el contenido de las normas jurídicas, y en la medida que luzcan más o menos razonables o compatibles con la Constitución se las mantendrá en el derecho, pero si se advierte un déficit moral grave, se las invalidará o se promoverá su mejoramiento racional o moral. La jurisprudencia constitucional y convencional está plagada de invocaciones a la moral contenida en los principios o derechos humanos que justifican el rechazo de normas o comportamientos jurídicos, e incluso sentencias que orientan o exhortan al legislador o gobernante sobre las normas legales o administrativas a crearse". VIGO (2015), p. 297.

94 Ver: KELSEN (1995)

${ }^{95}$ Ver: ALEXY (2004a), p. 227.

96 "El panorama teórico descripto se complica a partir de la sustitución del Estado de Derecho Legal por el Estado de Derecho Constitucional (EDC), es decir, cuando después de la caída del nazismo se condena a sus jerarcas por cumplir la "ley" y violar el "derecho", y así superándose esa sinonimia, se identifica al "derecho" con los derechos humanos cuyo fundamento es la dignidad propia de todo ser humano, y consiguientemente, es titular de los mismos todo miembro de la especie humana". Será la Ley Fundamental de Bonn del 49 la que consagrara positivamente la vigencia de ese "derecho" que es superior a la ley y cuya violación puede generar responsabilidades jurídicas, no obstante lo que disponga la ley. De ese modo se deja de lado el postulado rousseauniano de la voluntad general infalible, y se instituyen tribunales constitucionales con competencia como para asegurar que impere la prevalencia del derecho sobre la ley". VIGO (2015), p. 362.

${ }^{97}$ Ver: VIGO (2012), p. 27 
adaptó a la nueva realidad jurídica, adaptando para ello el rol del tribunal constitucional y la jurisdicción constitucional misma.

En consonancia con lo anterior, la jurisprudencia constitucional se ha encargado de dotar de contenidos a la justicia transicional, utilizando para ello los principios constitucionales ${ }^{98}$, los cuales no solo se encuentran en el plano deontológico del derecho ${ }^{99}$ y por ello sirven de orientación en la producción de reglas ${ }^{100}$, sino que los derechos constitucionales, particularmente los fundamentales, tienen de base un principio constitucional, lo cual implica su redefinición dogmática ${ }^{101}$.

El paradigma constitucional que entraña el rol fundamental de los principios constitucionales, implica entonces la erosión del positivismo jurídico ${ }^{102}$, con la consecuente resignificación del sistema de fuentes ${ }^{103}$, en tanto que se incluyen elementos de moral en el derecho ${ }^{104}$, los cuales serán apuntalados por la jurisprudencia constitucional, la nueva encargada de dotar de contenidos al derecho, generando sistemas jurídicos débiles, en oposición a los sistemas

98 "Llamo «principio» a un estándar que ha de ser observado, no porque favorezca o asegure una situación económica, política o social que se considera deseable, sino porque es una exigencia de la justicia, la equidad o alguna otra dimensión de la moralidad". DWORKIN (1989), p. 72.

99 "El punto decisivo para la distinción entre reglas y principios es que los principios son normas que ordenan que algo sea realizado en la mayor medida posible, dentro de las posibilidades jurídicas reales existentes. Por lo tanto, los principios son mandatos de optimización, que están caracterizados por el hecho de que pueden ser cumplidos en diferente grado y que la medida debida de su cumplimiento no sólo depende de las posibilidades reales, sino también de las jurídicas. El ámbito de las posibilidades jurídicas es determinado por los principios y reglas opuestos". ALEXY (1993), p. 86.

100 "Lo que aquí puede esperarse puede ser caracterizado - utilizando una terminología tradicional- como la parte general de la dogmática de los derechos fundamentales. Su base la constituyen la teoría de los principios expuesta en el tercer capítulo y la teoría de las posiciones jurídicas básicas elaborada en el cuarto capítulo. La teoría de los principios es "una axiología exenta de sup osiciones insostenibles. Habrá que mostrar que no es posible una dogmática adecuada de los derechos fundamentales sin una teoría de los principios". ALEXY (2004 b), p. 25.

101 "Lo que aquí puede esperarse puede ser caracterizado - utilizando una terminología tradicional- como la parte general de la dogmática de los derechos fundamentales. Su base la constituyen la teoría de los principios expuesta en el tercer capítulo y la teoría de las posiciones jurídicas básicas elaborada en el cuarto capítulo. La teoría de los principios es "una axiología exenta de sup osiciones insostenibles. Habrá que mostrar que no es posible una dogmática adecuada de los derechos fundamentales sin una teoría de los principios". ALEXY (1993), p. 25.

102 "Me propongo llevar un ataque general contra el positivismo y, cuando sea necesario dirigirlo contra un blanco en particular, usaré como tal la versión de H.L.A. Hart. Mi estrategia se organizará en torno del hecho de que cuando los juristas razonan o discuten sobre derechos y obligaciones jurídicas, especialmente en aquellos casos difíciles en que nuestros problemas con tales conceptos parecen agudizarse más, echan mano de estándares que no funcionan como normas, sino que operan de manera diferente, como principios, directrices políticas y otro tipo de pautas. Argumentaré que el positivismo es un modelo de y para un sistema de normas, y so stendré que su idea central de una única fuente de derecho legislativa nos obliga a pasar por alto los importantes papeles de aquellos estándares que no son normas". DWORKIN (1989), p. 72.

103 “La presencia de los principios en el ordenamiento jurídico repercute directamente en la teoría de las fuentes del derecho, poniendo en crisis el cuadro tradicional ligado a las normas generales (ley y costumbre jurídica) o al esquema algo remozado que incluye la jurisprudencia y los actos jurídicos. Si los principios son aquella juridicidad radical y preexistente, y por ende informadora - positiva o negativamente- de todo el sistema jurídico, resulta muy difícil sostener una aplicación supletoria de los mismos en defecto de la ley y el derecho consuetudinario". VIGO (2001), p. 87.

104 "Atienza indica como otra característica relevante del neoconstitucionalismo, la tesis de que entre el Derecho y la Moral exis te una conexión, no solo en cuanto al contenido, sino de tipo conceptual. En última instancia, una conexión necesaria, que puede ser interpretada en los siguientes términos: "cualquier decisión jurídica y en particular la decisión judicial, está justificada si deriva, en última instancia, de una norma moral". Pero esa consecuencia se deriva del carácter protagónico que deben asumir los jueces en la teoría neoconstitucionalista, en donde la tarea interpretativa asume un rol central, conformador del derecho. Precisamente, lo que permite la aplicación del derecho basada en principios es la posibilidad de que los jueces acudan a razones morales que justifican regular los casos de determinada manera. Ponderar principios, a juicio de Moreso, conduce inevitablemente al razonamiento moral. En efecto, no olvidemos que, siguiendo la conocida explicación de Dworkin, los principios poseen una dimensión de peso o de importancia de la cual carecen las normas. Y es precisamente esta dimensión, la que hace que los principios deban ser comparados entre sí, y el caso resuelto según el peso relativo atribuido a los diversos principios concurrentes. En todo caso, se hace ver que el encargado de "sopesar" dichos principios en juego es el juez, quien debe efectuar la ponderación en el marco de un caso particular. La apelación a la razón práctica es más que evidente: si bien hay un sustento teórico, el derecho se decide en el aquí y ahora, en el contexto del caso que el juez debe resolver". PORTELA (2009), p. 43. 
fuertes cerrados de estilo kelseniano ${ }^{105}$. Esto genera un escenario borroso o difuso, en donde la argumentación va a estar mediada por componentes jurídicos y no jurídicos que sustentan la solución de los $\operatorname{casos}^{106}$, como los principios morales que son intrínsecos a los derechos fundamentales ${ }^{107}$, por ejemplo.

Así las cosas, el derecho posmoderno puede caracterizarse a partir de cinco tensiones, según García Inda ${ }^{108}$ : multiplicidad, flexibilidad, levedad, rapidez y paradoja. La multiplicidad corresponde a nuevas formas de regulación diferentes a las establecidas por el monopolio estatal; la flexibilidad se refiere a que el discurso jurídico ha adquirido características de ductilidad que se reflejan en el uso continuo de conceptos jurídicos indeterminados que acercan las discusiones jurídicas a espacios no jurídicos; la levedad radica en las dificultades para lograr sustentar un estatuto epistemológico sólido para la ciencia del derecho después de la erosión del positivismo; la rapidez corresponde a la situación de inestabilidad temporal de los paradigmas jurídicos, los que son adoptados y desechados a la misma velocidad de cambio del mundo, lo cual supone que aparezcan fenómenos como la hipertrofia normativa, es decir, la expedición contante de gran cantidad de normas que hacen de la vieja presunción del conocimiento de la ley por parte del conglomerado, nada más que una quimera; la paradoja se desprende de la multiplicidad, en donde el discurso jurídico basado en la lógica formal abre paso a un sistema dinámico en donde la entrada y salida permanente de actores y de elementos conllevan a una reconfiguración, tanto del discurso como de sus elementos internos.

El derecho posmoderno implica la reconfiguración del derecho mismo, dejando de lado, para ello, la concepción de un derecho basado en las reglas de la lógica formal, de forma exclusiva, dada la pretensión científica racionalista del positivismo. Excluir a la justicia del derecho significó la vulneración de los derechos inherentes al ser humano, pero de forma paradójica, conllevó a repensar el derecho mismo para darle cabida a la justicia y a los derechos, generando rupturas con el positivismo y que llevaron a una reconfiguración tanto en el sistema de fuentes del derecho como de sus preocupaciones.

\section{La justicia transicional como manifestación concreta de la posmodernidad en el derecho}

Así como la teoría del derecho entrañó una ruptura en su concepción modernista, al considerar a los derechos humanos como nueva fuente de validez jurídica, el derecho penal también fue impactado por las disrupciones derivadas de la posmodernidad. El derecho penal de la modernidad se estructuró sobre la base de que el criminal ostenta una conducta "desviada" que

\footnotetext{
105 "Como lo había advertido Kelsen, la presencia de "principios" en el sistema jurídico es un factor perturbador del mismo en orden a establecer claramente su contenido normativo, su coherencia y su jerarquía. Por ello los neoconstitucionalistas no positivistas desde el momento que proclaman -como Alexy- principios y sus exigencias morales de "lo mejor posible", deben renunciar a reconstrucciones del derecho vigente como un "sistema fuerte" al modo que lo propuso la teoría pura con su famosa pirámide jurídica normativa. En definitiva, los sistemas jurídicos compatibles con los planteos neoconstitucionalistas deben ser "débiles", "abiertos", "dinámicos" y "problemáticos", más aún, en sus propuestas no sólo aparece debilitada la importancia del sistema sino que es puesto a prueba en cada caso, y así más que obsesionarse por identificar el lugar que tiene cada regla dentro del derecho vigente, la pretensión es encontrar criterios ordenadores de normas y principios, un buen ejemplo de ello puede ser la fórmula del bloque de constitucionalidad". VIGO (2015), p. 375.

106 "El derecho ha difuminado sus límites por lo que el origen de sus normas puede no estar ya determinada por su validez formal; la unidad que antes exhibía en torno a la cerrada distinción entre estándares jurídicos y no jurídicos (y la consiguiente apertura en cuanto a la solución de los casos, signada por la discrecionalidad) pasa a ser una unidad en la forma de una solución correcta para cada caso (y la consiguiente apertura en cuanto a la identificación de los estándares jurídicos)". MORALES (2016), p. 29.

107 Ver: ORTíz (2016), p. 16.

${ }^{108}$ GARCÍA (2001).
} 
debe ser objeto de corrección mediante el ejercicio del ius puniendi del Estado, en aras de que el individuo pueda ser objeto de un proceso de "resocialización" a través de la pena ${ }^{109}$, lo cual se funda sobre un marco característico que distinguió al derecho penal de la modernidad ${ }^{110}$ y que se pueden resumir de esta manera: i) el castigo ya no se entiende como sufrimiento, por lo que se van a prohibir las penas consistentes en torturas, prácticas propias de la pre-modernidad en donde lo importante es la expiación de las culpas a través del dolor; ii) las penas se imponen de acuerdo con el principio de equivalencia del daño producido, pero no como resignificación de la ley del Talión, sino en virtud de la proporción y duración de la pena; iii) la función principal de la pena es la resocialización del individuo que presenta la conducta desviada; iv) la respuesta al delito debe ser absolutamente racional, sin lugar para las pasiones o emociones individuales, por lo que el ejercicio punitivo se encuentra fuertemente reglado, revistiéndose de carácter científico; v) el sistema penal busca el fin último de una sociedad libre de delitos, por lo que deposita esta utopía en los profesionales que, haciendo uso de la ciencia, avanzarán en este sentido. Sin embargo, un análisis detallado de reformas penales de las últimas décadas evidencia una ruptura con la modernidad penal, lo que puede interpretarse como la llegada de la posmodernidad a esta materia ${ }^{111}$.

El influjo de la modernidad en el derecho penal, parte de un nuevo punitivismo en donde se pretende un castigo cada vez más duro, que genera rompimientos en la persona que sujeta del derecho penal, no pretendiendo resocializarlo sino simplemente castigarlo, con penas tan altas que carecen de toda proporcionalidad y que sirvan de ejemplo disuasorio para los demás ${ }^{112}$. Ello refleja solo una de las rupturas de la modernidad en materia del derecho penal, sin embargo, para pensar a la justicia transicional como una manifestación de la posmodernidad en el derecho, el análisis parte de pensar el impacto de la posmodernidad en la guerra ${ }^{113}$, dado que la guerra es la razón de que exista la justicia transicional.

La guerra moderna ha partido de la idea del Estado como "la más elevada conjunción de unidad política, monopolio de la soberanía y la fuerza, realización de la razón y la voluntad humana"114. En la posmodernidad, el Estado deja de ser el eje central de la política, en desmedro de este van a aparecer otras unidades políticas que se vuelven relevantes para el análisis, lo cual se hace manifiesto en la guerra. Por "unidad política será toda aquella entidad que pueda apelar de manera efectiva al casus belli, determinar al enemigo y disputar por un derecho de dominación" 115 . La determinación de estas unidades políticas, depende de la caracterización de cada conflicto, así pueden considerarse como tales a ejércitos establecidos, a guerrillas, a grupos paramilitares, a bandas criminales y a cualquier otro actor que pueda disputar el derecho de dominación en un conflicto bélico.

\footnotetext{
109 Ver: DEL ROSAL (2009), pp. 57-58.

${ }^{110}$ Ver: DEL ROSAL (2009), pp. 58-59.

111 "Sin embargo, en nuestra opinión, y siguiendo en este punto la de otros autores como Pratt o Hallsworth, sí que son apreciables discontinuidades o rupturas con el proyecto penal de la modernidad. Así, como ha señalado este último, el restablecimiento de la capacidad de infligir daño y humillación como estrategia penal legítima, haciendo visibles la condición de delincuente y el cumplimiento de sanciones; la desatención a las exigencias del principio de humanidad y proporcionalidad, con sentencias arbitrarias y desproporcionadas; $y$, finalmente, la ejecución penitenciaria de sanciones que carecen del menor sentido productivo, en términos de inversión en el material humano, de modo que se haga posible o, al menos, se intente la recuperación social del delincuente, desatendiéndose, de esa forma, palmariamente su bienestar futuro, son tendencias cada vez más sobresalientes en la filosofía que inspira las reformas de nuestros sistemas penales de los últimos lustros, y eso significa una severa ruptura con el proyecto penal moderno". DEL ROSAL (2009), p. 61.

112 Ver: DEL ROSAL (2009), p. 11.

${ }^{113}$ En este texto la palabra guerra no se utiliza únicamente de la forma técnica a la que se refieren los Convenios de Ginebra, sino que también corresponde a un vocablo genérico más en el sentido de conflicto.

114 GIRALDO (2009), p. 67.

115 GIRALDO (2009), pp. 74-75.
} 
La primera consecuencia de la desestatalización de la guerra como visión unívoca de la misma, herencia de la modernidad, radica en que el derecho que regula la guerra pierde su eficacia, su razón de ser ${ }^{116}$.

La justicia transicional constituye una nueva lengua común en materia de resolución de conflictos. Una nueva forma del derecho de la guerra cuyo propósito, más que humanizarla, es su superación a través de una transición política, que permita dejar de lado las condiciones que la originaron, o en un sentido más amplio, que motivaron el acaecimiento del conflicto, por ello, la transición supone un proceso de estabilización, entendiendo que las causalidades originarias, pueden corresponder a un caleidoscopio de posibilidades, no solo porque la ruptura institucional puede darse por el enfrentamiento de dos o más partes, sino por una ruptura del sistema democrático mismo, verbigracia con una dictadura, por lo que la transición puede incluir elementos de rediseño institucional del Estado ${ }^{117}$. Ahora bien, no existen fórmulas estandarizadas para pensar una receta de justicia transicional, sino que cada caso debe ser analizado de forma específica, verbigracia, no es lo mismo un estado en guerra civil a un estado en donde una grave crisis política haya generado una pauperización de la economía de tal magnitud, que la represión haya implicado la vulneración sistemática de los derechos humanos, y aun cuando en ambos casos es posible pensar sistemas de justicia transicional que faciliten la transición, el sistema que se adopte debe reflejar los contornos de las causalidades que llevaron a esa situación. Por ello, como nuevo derecho de la guerra, la regulación de justicia transicional no puede circunscribirse a la guerra clausewitziana ${ }^{118}$ tradicional, sino que, se reitera, es requerida la revisión de las causalidades de esta para la comprensión de sus actores entre los que aparecen nuevas unidades políticas que deben sujetarse a la nueva regulación. En el caso colombiano los actores son de la más variada índole: grupos guerrilleros, grupos paramilitares transmutados en bandas criminales, grupos de narcotraficantes y las fuerzas militares y de policía como representantes legítimos del Estado, sin embargo también aparecen sectores de la institucionalidad estatal (políticos, militares, policías) que entraron en un contubernio con actores ilegales como paramilitares y guerrillas ${ }^{119}$, que hicieron que el Estado perdiera su condición de sí y entrara en una escisión del sujeto que Giraldo ${ }^{120}$ denomina como esquizofrenia de Estado. Las reglas clásicas de la guerra no permiten atender el entramado de actores que se integran en un conflicto como el colombiano, por ejemplo, en donde el actor Estado participa tanto desde la legitimidad como desde alianzas ilegales.

Adicionalmente, la justicia transicional entraña en su propia concepción, y en su justificación, la incorporación de estándares internacionales en derechos humanos en materia de verdad, justicia, reparación y garantías de no repetición ${ }^{121}$. Es decir, no solo se trata de una transición política, sino que esa transición debe darse bajo el marco establecido por los estándares

\footnotetext{
116 "Sin embargo, ni la naturaleza de la guerra posmoderna ni los propósitos de sus combatientes coinciden con sus normas, y ello ha hecho que sea un parámetro frustrante para todo intento jurídico de regular la guerra. La guerra posmoderna involucra a civiles como pretexto, reclutas y víctimas de la contienda; asume al enemigo totalmente de manera que sus civiles, bienes, ideas y símbolos se incluyen entre los objetivos bélicos; el armamento que se usa, la ausencia de teatro de operaciones, la recurrencia del ardid, impiden la aplicación del principio de distinción. Pero no se trata sólo de que tales normas no se pueden aplicar: los guerreros posmodernos no las quieren aplicar". GIRALDO (2009), pp. 89-90.

${ }^{117}$ Ver: La justicia transicional puede concebirse como el vehículo que permite el "tránsito en uno de los siguientes supuestos: de un estado de vulneración sistemática de derechos humanos a uno de cesación de dicha vulneración, de un régimen totalitario a un régimen democrático o de un estado de conflicto a uno de cesación del conflicto, que implique la construcción de un posconflicto". RÚA (2016), p. 458.

${ }^{118}$ Ver: CLAUSEWITZ (1984).

${ }^{119}$ Ver: RÚA (2015), pp. 83-84.

${ }^{120}$ GIRALDO (2010), p. 218.

${ }^{121}$ Ver: RÚA (2015), pp. 78-79.
} 
internacionales mencionados, no es una transición a cualquier costo, sino una transición que garantice que no habrá impunidad ${ }^{122}$.

También se debe tener presente que en la justicia transicional se presenta una resignificación de las víctimas, cuyos derechos van a ser reconocidos y ponderados como eje de las normas de justicia transicional. Ello presenta una tensión entre víctimas y victimarios, puesto que la justicia esperada por las víctimas, no será en el sentido del derecho penal moderno, sino partiendo de una forma de justicia diferente, en donde la no impunidad se garantice precisamente con la satisfacción de los estándares internacionales en derechos humanos. Esta situación, sin embargo, resulta problemática, dado que implica una reflexión profunda respecto de qué tantas concesiones se está dispuesto a realizar, dicho en otras palabras, qué tanto grado de impunidad está contemplado con el fin de alcanzar la reconciliación, la pregunta por la posibilidad de perdonar lo imperdonable ${ }^{123}$.

En síntesis, si uno de los elementos importantes en la ruptura del derecho positivo como metarrelato de la modernidad, lo constituye la incorporación de la búsqueda de la justicia como propósito del Derecho, ello se refleja de manera palmaria en la justicia transicional, en donde la búsqueda de la justicia se traduce en la incorporación de estándares internacionales de derechos humanos, además de que esta normatividad debe aplicarse a pluralidad de actores de diversa índole, unos legales y otros ilegales, y otros legales en connivencia con los ilegales.

El gran temor que suscita la posmodernidad es que, al afectarse el metarrelato fundante de la racionalidad, la superficialidad y la irracionalidad permeen todas las esferas antes dominadas por la razón. Este temor no ha sido ajeno al mundo del derecho: la irracionalidad como nuevo patrón de generalización en la construcción de normas jurídicas. Sin embargo, Kaufmann ${ }^{124}$ considera que la posmodernidad, lejos de llevar a una irracionalidad en el derecho, lo que supone son nuevos desafíos que se constituirán en el eje de discusión de la filosofía del derecho en la posmodernidad, se trata de las preguntas guías sobre las que se estructura la justicia transicional: la pregunta por la paz duradera, por la distribución de bienes y de cargas, por la diferencia entre derecho y entuerto y sobre todo por la justicia, son la base de discusión de los modelos de justicia adoptados en épocas de transición. La superación del conflicto y la transición política que ello conlleva, con las pretensiones de atacar las razones justificatorias del mismo conflicto y el establecimiento de estándares internacionales en materia de garantías de no repetición, se realzan sobre la pregunta por la paz duradera. Igualmente la búsqueda de una justicia para las víctimas y el restablecimiento de ciertas condiciones de existencia previas a su afectación, como la restitución de tierras o la reparación integral, se edifican sobre la pregunta por la distribución de bienes y cargas. A su vez, la diferencia entre derecho y entuerto parte del hecho de que en el pasado se ponderó la búsqueda de la paz, con la consecuente desmovilización de actores armados ilegales, por encima de los

\footnotetext{
122 "Junto con los factores que propician las condiciones de transformación política y social de la sociedad, la justicia transicional conlleva a la aplicación del concepto "justicia", puesto que en muchas transiciones ese componente fue excluido de la deliberación pública, tal y como sucedió con la transición hacia la democracia de los regímenes dictatoriales del Cono Sur, en donde la negociación política implicó la impunidad para los responsables de las violaciones sistemáticas a los derechos humanos durante estos regímenes, situación que pretendió ser corregida tiempo después". RÚA (2014), p. 197.

123 Ver: UPRIMNY Y SAFFON (2006), p. 114.

124 "Si la imagen que tengo ante mí no me engaña, la filosofía del derecho de las generaciones venideras no tendrá rasgos posmodernos irracionales, místicos, ni tampoco estará caracterizada por un creciente ascenso de la razón formal, técnica, funcionalista. Más bien deberá recordar de nuevo su tarea original, esto es, dar respuestas a los interrogantes que los hombres plantean a la filosofía del derecho: la pregunta sobre la diferencia entre derecho y entuerto, la pregunta sobre las condiciones de una sociedad bien ordenada, la pregunta sobre una paz duradera, la pregunta sobre los bienes, posibilidades y cargas, que cada uno recibirá como propios, la pregunta sobre la medida de justicia que a los humanos nos es posible realizar. A la larga no podremos tolerar una filosofía del derecho que casi exclusivamente trata de problemas formales o se agota en metateorías". KAUFMANN (2014), pp. 70-71.
} 
derechos de las víctimas, valiéndose para ello de indultos y amnistías que dejaron una estela de impunidad; pues bien, lo que se pretende con la justicia transicional es precisamente la lucha contra la impunidad sin que ello conlleve a un sacrificio de la paz y la reconciliación nacional, por ello la incorporación de estándares internacionales de derechos humanos en los contenidos de las normas de justicia transicional. Todas estas cuestiones anteriores desembocan en la pregunta por la justicia y de alguna manera la resuelven ${ }^{125}$.

La justicia transicional lo que busca es precisamente llegar al punto medio necesario entre la paz y la justicia ${ }^{126}$, no la superación de una por la otra, como lo es en el caso de las amnistías o indultos generalizados, en donde, a cambio de la paz y la reconciliación, se concedió la impunidad a través de estos mecanismos; muy al contrario, la justicia transicional entraña el compromiso de que si bien no se atiende al ius puniendi tradicional, la respuesta tampoco se encuentra en la impunidad, sino en una forma diferente de justicia ${ }^{127}$, en donde se garanticen los derechos de las víctimas a través del cumplimiento de estándares internacionales en derechos humanos.

Adicionalmente, la justicia transicional ha sido impactada fuertemente por el constitucionalismo contemporáneo, caracterizado, entre otras cosas, por la preponderancia de la jurisprudencia del Tribunal Constitucional y el reconocimiento de principios morales que gozan de una manifestación jurídica bajo la forma de derechos y que sirven de orientación para la producción de reglas ${ }^{128}$. En materia transicional pueden presentarse ajustes a la Constitución o un completo cambio constitucional ${ }^{129}$, pero lo cierto es que se hace absolutamente necesario un marco jurídico que sirva de soporte a la transición ${ }^{130}$. Por tal razón el constitucionalismo de los procesos transicionales parte por estructurarse paso a paso, en gran medida por los fallos de la jurisprudencia constitucional, y por elevar, a rango constitucional, bien sea los acuerdos que permiten la transición o los principios que permiten la interpretación de los mismos ${ }^{131}$.

En el caso colombiano, por ejemplo, la justicia transicional fue elevada a categoría constitucional, mediante una serie de Actos Legislativos ${ }^{132}$ proferidos, principalmente, en el año 2017, justo después de la firma del Acuerdo Final con la guerrilla de las FARC-EP (Fuerzas Armadas Revolucionarias de Colombia y Ejército del Pueblo, respectivamente), conocido como el Acuerdo del Teatro Colón ${ }^{133}$, aun cuando en el año 2012 se presentó un antecedente fundamental con el Marco Jurídico para la Paz, que correspondió a un primer intento de elevar a categoría constitucional algunos principios que servirían de base para la entonces incipiente negociación entre el Gobierno colombiano y las FARC-EP. Precisamente la jurisprudencia constitucional que se desprendió de la interpretación de esa reforma, fue la que permitió consolidar a la justicia transicional como un

\footnotetext{
${ }^{125}$ Como bien lo señala Atienza: "la justicia no es un ideal irracional. Es simplemente un ideal o, si se quiere, una idea regulativa; no una noción de algo, sino una noción para algo: para orientar la producción y la aplicación del Derecho". ATIENZA (2012), p. IX.

${ }^{126}$ Ver: NAJAR (2009), p. 74.

127 Ver: BURCHARD (2018).

${ }^{128}$ Ver el punto 4 de este escrito.

129 Ver: TEITEL (2017), pp. 457-507.

130 "Los datos de las investigaciones y la lógica del proceso de fracaso del Estado sugieren que la paz y la seguridad, el desarme y la desmovilización, y el restablecimiento de la confianza mutua y la fe necesitan acompañarse de la recuperación o la reconstrucción de los procesos legales. Una fuerza policial de posconflicto no puede funcionar en ausencia de normas nacionales". ROTBERG (2007), p. 225.

131 "La construcción de nuevos acuerdos constitucionales en períodos de cambios políticos radicales está inspirada en una concepción transicional de la justicia constitucional. El derecho constitucional es comúnmente conceptualizado como la forma más avanzada del derecho. Sin embargo, el constitucionalismo transicional es ambivalente en su direccionalidad; para la generación revolucionaria, el contenido de los principios de la justicia constitucional se relaciona con la injusticia pasada. Desde una perspectiva transicional, lo que se considera constitucionalmente justo es contextual y contingente, y está relacionado con el intento de transformar los legados de las injusticias cometidas en el pasado". TEITEL (2017), p. 469.

${ }^{132}$ Por acto legislativo se entiende el acto reformatorio de la Constitución Política en el ordenamiento jurídico colombiano.

${ }^{133}$ Ver: Acuerdo Final para terminación del conflicto y la construcción de una paz estable y duradera (noviembre 24 de 2016).
} 
paradigma que entraña una nueva forma de ver la justicia, superando la idea de castigo que subyace en la clásica versión de la justicia retributiva tan propia del derecho penal y para ello supo ubicar a la justicia transicional como un principio constitucional ${ }^{134}$ derivado de valores y principios constitucionales como el Estado Social de Derecho ${ }^{135}$ y la paz misma, la cual se comporta como derecho, principio y valor constitucional ${ }^{136}$. Así las cosas, elementos como la verdad o la alternatividad de la pena, por ejemplo, fueron desarrollados por la Corte Constitucional colombiana y sentaron las bases de la copiosa jurisprudencia expedida por esa corporación entre los años 2017 y 2018, como consecuencia de la aprobación del Acuerdo Final.

\section{Conclusión}

Los procesos de ruptura de la modernidad, denominados como posmodernidad, también han impactado el mundo del derecho, particularmente con el derecho positivo, que se erigió en el gran metarrelato jurídico de la modernidad. Esta ruptura se dio a mediados del siglo XX como consecuencia de la shoah, representada en Aushwitz como símbolo de la pérdida de la razón. A partir de ese momento, la no repetición de Aushwitz se convertiría, en términos de Adorno, en un nuevo imperativo categórico. Ello conllevó a que se pensara en la adopción de un sistema universal de derechos humanos inspirado en el iusnaturalismo racional, justificado en la búsqueda de la justicia por sobre los problemas formalistas respecto de la validez del derecho, lo que significó una disrupción del discurso cientifista que envolvía al derecho positivo. Esa ruptura generó que todas las esferas del derecho comenzaran a repensarse, fruto de lo cual aparecen nuevos modelos como la justicia transicional, la cual incorpora contenidos políticos a la normatividad - los que se refieren a la transición en sí- además de contenidos de justicia y de lucha contra la impunidad, representados en la integración a la norma de estándares internacionales de derechos humanos; es decir, la normatividad de justicia transicional incorpora contenidos políticos y contenidos jurídicos basados en estándares en derechos humanos que resultan herederos de las rupturas con la modernidad representada en el iuspositivismo. Además, el actor estatal, eje de las discusiones de la filosofía política de la modernidad, va a dar pie a la aparición de otras unidades políticas, consistentes en los actores involucrados en los conflictos y que van a ser sujetos de las normas de justicia transicional. Por todo ello, bien puede pensarse que la justicia transicional resulta en una heredera de las rupturas sufridas por el positivismo como metarrelato de la modernidad, lo que va a representar una manifestación concreta y contemporánea de la posmodernidad.

\section{BIBLIOGRAFÍA CITADA}

ADORNO, THEODOR (2005): Dialéctica Negativa. La Jerga de la autenticidad. Obra completa 6 (Madrid, Ediciones Akal).

\footnotetext{
134 "Si bien la Carta Constitucional originalmente adoptada en 1991 no se refería expresamente al concepto de justicia transicional o justicia de transición, la jurisprudencia constitucional lo sustentó en disposiciones normativas específicas de la Carta Política y ahondó en su tratamiento en cuestiones tales como su definición, su aplicabilidad en situaciones concretas, y en el papel de las autoridades judiciales, legislativas y administrativas en tanto la resolución de sus tensiones inherentes.

(...) La Corte reconoció, además, la pertinencia de las medidas de transición dentro de un contexto amplio, admitiendo su pertinencia tanto para situaciones de posdictadura como de posconflicto. Incluso, para sellar la disputa sobre el ámbito de su aplicación, la Corte se ha pronunciado encontrando ajustada la aplicación de mecanismos transicionales aun durante la vigencia del conflicto". SÁNCHEZ e IBÁÑEZ (2014) pp. 112-114.

135 Ver: RÚA Y CASTILLO (2015)

136 Ver: MORENO (2014).
} 
Taurus).

(2001): Minima Moralia. Reflexiones sobre la vida dañada, tercera edición (Madrid,

ALEXY, ROBERT (2004 A): “Una defensa de la fórmula de Radbruch”, en: Vigo, Rodolfo (Compilador), La injusticia extrema no es derecho. De Radbruch a Alexy (Buenos Aires, La Ley), pp. 75-95.

(2004 B): El concepto y la validez del derecho, segunda edición (Barcelona, Editorial Gedisa

S.A.).

(1993): Teoría de los Derechos Fundamentales (Madrid, Centro de Estudios

Constitucionales).

ANSUÁTEGUI ROIG, FRANCISCO JAVIER (2011): Filosofía del Derecho y Constitucionalismo. Vertientes y Problemas (Cali, Universidad Autónoma de Occidente, Instituto de Derechos Humanos Bartolomé de las Casas de la Universidad Carlos III de Madrid).

ATIENZA, MANUEL (2012): Tras la justicia (Barcelona, Ariel).

BAUMAN, ZYGMUNT (2011): Modernidad y Holocausto, sexta edición (Madrid, Ediciones Sequitur).

BENJAMIN, WALTER (2013): Tesis sobre la historia y otros fragmentos (Bogotá D.C., Ediciones Desde Abajo).

Bernal GÓMEZ, BeATRIZ (2010): Historia del Derecho (México, Nostra Ediciones).

BEUCHOT, MAURICIO (2009): Historia de la filosofía en la posmodernidad, segunda edición (México, Editorial Torres Asociados).

BOBBIO, NORBERTO (2004): El problema del positivismo jurídico, primera edición, octava reimpresión (México, Fontamara).

Debate).

(1993): Teoría General del Derecho, primera edición, segunda reimpresión (Madrid,

BOtero BERNAL, ANDRÉS (2014): El positivismo jurídico en la historia (Medellín, Universidad de Medellín).

BRIESKORN, NORBERT (1993): Filosofía del Derecho (Barcelona, Herder).

BURCHARD, CRISTOPH (2018): “¿Es efectivo el castigo penal de combatientes en un conflicto armado? Reflexiones iniciales sobre maneras para vencer la ignorancia sobre la eficacia de soluciones penales en la justicia transicional?", en: A.A.V.V., Justicia transicional y Derecho penal internacional (Bogotá D.C., Siglo del Hombre Editores). 
CASSIRER, ERNST (1993): Filosofía de la llustración, tercera edición, cuarta reimpresión (Madrid, Fondo de Cultura Económica).

CASULLO, NICOLÁS (2009): "La modernidad como autorreflexión", en: A.A.V.V., Itinerarios de la Modernidad: corrientes del pensamiento y tradiciones intelectuales desde la llustración hasta la posmodernidad, primera edición, quinta reimpresión (Buenos Aires, Eudeba), pp. 9-22.

CHEVALIER, JACQUES (2011): El Estado posmoderno (Bogotá D.C., Universidad Externado de Colombia).

CLAUSEWITZ, CARL VON (1984): De la guerra (Barcelona, Editorial Labor).

CRUZ KRONFLY, FERNANDO (2007): La derrota de la luz: ensayos sobre modernidad, contemporaneidad y cultura (Cali, Universidad del Valle).

CUARTAS RESTREPO, JUAN MANUEL (2015): La experiencia hermenéutica (Medellín, Fondo Editorial Universidad EAFIT).

DEL RÍO, ANDRÉS (2014): “Dictadura, democracia y Justicia Transicional en Brasil: Trayectoria y Legados del Supremo Tribunal Federal", en: DADOS, Revista de Ciências Sociais (Vol. 57, N 4), pp. 11691202.

Del Rosal Blasco, BeRnardo (2009): “¿Hacia el Derecho Penal de la Posmodernidad?”, en: Revista Electrónica de Ciencia Penal y Criminología ( $\left.N^{\circ} 11-08\right)$, pp. 1-64.

DESCARTES, RENÉ (1975): Discurso del Método, décima edición (Buenos Aires, Aguilar).

DÍAZ, ELÍAS (1998): Curso de Filosofía del Derecho (Madrid, Marcial Pons).

DIÉGUEZ, ANTONIO (2006): "La ciencia desde una perspectiva postmoderna: Entre la legitimidad política y la validez epistemológica”. Disponible en: http://webpersonal.uma.es/ DIEGUEZ/hipervpdf/CIENCIAPOSTMODERNA.pdf [visitado el 14 de julio de 2017].

DWORKIN, RONALD (1989): Los Derechos en serio, segunda edición (Barcelona, Editorial Ariel S.A.).

FEATHERSTONE, MIKE (2000): Cultura de consumo y posmodernismo (Buenos Aires, Amorrortu).

FEIERSTEIN, DANIEL (2008): El genocidio como práctica social: entre el nazismo y la experiencia argentina (Buenos Aires, Fondo de Cultura Económica).

FORSTER, RICARDO (2009): "La crisis de la racionalidad moderna", en: A.A.V.V., Itinerarios de la Modernidad: corrientes del pensamiento y tradiciones intelectuales desde la Ilustración hasta la posmodernidad (Buenos Aires, Eudeba), pp. 143-163.

GARCÍA INDA, ANDRÉS (2001): "Cinco apuntes sobre derecho y posmodernidad", en: Revista DOXA (N 24), pp. 235-248. 
GIDDENS, ANTHONY (1993): Consecuencias de la modernidad (Madrid, Alianza Editorial).

GIRALDO RAMíREZ, JORGE (2009): Guerra civil posmoderna (Bogotá D.C., Siglo del Hombre Editores, Instituto de Filosofía de la Universidad de Antioquia, Fondo Editorial Universidad EAFIT).

GOBIERNO DE COLOMBIA-FARC-EP (2017): Acuerdo Final para terminación del conflicto y la construcción de una paz estable y duradera (noviembre 24 de 2016) (Bogotá D.C., Ediciones Desde Abajo).

GRÜN, ERNESTO (1997): “El derecho posmoderno: un sistema lejos del equilibrio", en: Revista Telemática de Filosofía del Derecho ( $\left.\mathrm{N}^{\circ} 1\right)$, pp. 16-25.

HABERMAS, JÜRGEN (2008): "La modernidad, un proyecto incompleto", en: Foster, Hal (editor), La Posmodernidad, séptima edición (Barcelona, Kairós), pp. 19-36.

(Madrid, Taurus).

(1993): Discurso Filosófico de la Modernidad, primera edición, tercera reimpresión HARVEY, DAVID (2012): La condición de la posmodernidad: investigación sobre los orígenes del cambio cultural, segunda edición, primera reimpresión (Buenos Aires, Amorrortu).

HERVADA, JAVIER (2014A): ¿Introducción crítica al Derecho Natural?, segunda edición, primera reimpresión (Bogotá D.C., Temis).

(2014B): ¿Qué es el derecho?, segunda edición, primera reimpresión (Bogotá D.C., Temis).

HORKHEIMER, MAX (2003): Teoría Crítica (Buenos Aires, Amorrortu).

(1973): Crítica de la razón instrumental (Buenos Aires, Editorial Sur), segunda edición.

HORKHEIMER, MAXY ADORNO, THEODOR (1998): Dialéctica de la llustración. Fragmentos filosóficos, tercera edición (Madrid, Editorial Trotta).

JAMESON, FREDERIC (2008): "Posmodernismo y sociedad de consumo", en: Foster, Hal (editor), La Posmodernidad, séptima edición (Barcelona, Kairós), pp. 165-186.

KANT, IMMANUEL (1994): “Respuesta a la pregunta: ¿Qué es la llustración?”, en: Revista Colombiana de Psicología (N³), pp. 7-10.

KAUFMANN, ARTHUR (2014): La Filosofía del Derecho en la Posmodernidad, tercera edición (Bogotá D.C., Temis).

Colombia).

(2006): Filosofía del Derecho, segunda edición (Bogotá D.C., Universidad Externado de

KELSEN, HANS (2009): Teoría Pura del Derecho, cuarta edición (Buenos Aires, Eudeba). 
(2007): ¿Qué es la Teoría Pura del Derecho? (México, Fontamara).

(2005): ¿Qué es la Justicia? (México, Fontamara).

(1995): ¿Quién debe ser el defensor de la Constitución? (Madrid, Tecnos).

LÓPEZ AYLLÓN, SERGIO (1997): Las transformaciones del sistema jurídico y los significados sociales del derecho en México (México, Universidad Nacional Autónoma de México).

LYOTARD, JEAN FRANÇOIS (1994): La posmodernidad explicada a los niños, tercera edición (Barcelona, Gedisa).

(1987): La condición postmoderna. Informe sobre el saber (Madrid, Ediciones Cátedra).

MARGOT, JEAN PAUL (2008): Modernidad, crisis de la modernidad y posmodernidad (Cali, Universidad del Valle), segunda edición, primera reimpresión.

(2004): La Modernidad. Una ontología de lo incomprensible (Cali, Universidad del Valle), segunda edición.

MORALES LUNA, FÉLIX. (2016): “La dogmática en el Estado Constitucional de Derecho”, en: Priori Posada, Giovanni (Coordinador), Constitución, Derecho y derechos (Lima, Red Justicia, Derecho, Constitución y Proceso), pp. 19-30.

MORENO MILLÁN, FRANKLIN (2014): “El concepto de paz en la Constitución Política de Colombia de 1991: reconstrucción dialéctica de su significado a partir de la jurisprudencia de la Corte Constitucional", en: Revista de Derecho (Vol. 21, № 2), pp. 305-346. Disponible en: http://revistaderecho.ucn.cl/article/view/1915/1541 [visitado el 16 de mayo de 2019].

NAJAR, ESPERANZA (2009): Derecho a la verdad y justicia transicional en el marco de aplicación de la Ley de Justicia y Paz (Bogotá D.C., Grupo Editorial Ibáñez).

NINO, CARLOS SANTIAGO (1989): Ética y Derechos Humanos (Barcelona, Ariel).

ORTíz CABALLERO, RENÉ (2016): "Justicia y constitución: entre la modernidad y la posmodernidad" en Priori Posada, Giovanni (Coordinador), Constitución, Derecho y derechos (Lima, Red Justicia, Derecho, Constitución y Proceso), pp. 11-18.

PAPACCHINI, ÁNGELO (2003): Filosofía y Derechos Humanos (Cali, Universidad del Valle), tercera edición, segunda reimpresión.

PÉREZ LUÑO, ANTONIO ENRIQUE (2002): La universalidad de los derechos humanos y el Estado constitucional (Bogotá D.C., Universidad Externado de Colombia).

PÉREZ ROYO, JAVIER (1984): Las fuentes del derecho (Madrid: Tecnos). 
PORTELA, JORGE GUILLERMO (2009): “Los principios jurídicos y el neoconstitucionalismo”, en: Revista Díkaion (Vol. 23, № 18), pp. 33-54. Disponible en: http://dikaion.unisabana.edu.co/index.php/dikaion/article/view/1542/2112 [visitado el 18 de mayo de 2019].

PRIETO SANCHÍs, LUIS (2007): Teoría del Derecho (Madrid, Trotta), segunda edición.

RADBRUCH, GUSTAV (2009): Relativismo y Derecho (Bogotá D.C., Temis), segunda edición.

(1980): El Hombre en el Derecho (Buenos Aires, Ediciones Depalma).

ROTBERG, ROBERT (2007): “El fracaso y el colapso de los Estados-Nación. Descomposición, prevención y reparación", en: Rotberg, Robert, Clapham, Cristopher y Herbst, Jeffrey, Los Estados fallidos o fracasados: un debate inconcluso y sospechoso (Bogotá D.C.: Siglo del Hombre Editores, Universidad de los Andes, Pontificia Universidad Javeriana), pp. 151-237.

ROUSSEAU, JEAN JACQUES (2003): El contrato social o principios del derecho político (Buenos Aires, Editorial La Página S.A.).

RÚA DELGADO, CARLOS FELIPE (2016): "La justicia anamnética como construcción complementaria del paradigma de justicia transicional”, en: Revista lus et Praxis (Vol. 22, $\mathrm{N}^{\circ} 1$ ), pp. 455-492. Disponible en: http://www.revistaiepraxis.cl/ index.php/iepraxis/article/view/629/436 [visitado el 8 de agosto de 2016].

(2015): "Los momentos de la justicia transicional en Colombia", en: Revista de Derecho ( ${ }^{\circ}$ 43), $\quad$ pp. 71-109. Disponible en: http://rcientificas.uninorte.edu.co/index.php/derecho/article/view/6270/6745 [visitado el 18 de marzo de 2016].

(2014): "Prolegómenos para la aplicación de criterios de priorización de delitos en los procesos de Justicia y Paz en Colombia", en: Revista Latinoamericana de Derechos Humanos (Vol. 25, $\quad \mathrm{N}^{\circ} \quad 2$ ), $\quad$ pp. 193-220. http://www.revistas.una.ac.cr/index.php/derechoshumanos/article/view/6159/6142 [visitado el 24 de septiembre de 2016]

(2013): Política regulativa en la educación superior (Bogotá D.C.: Ecoe Ediciones).

RÚA DELGADO, CARLOS FELIPE Y CASTILLO CASTILLO, MARÍA LILIANA (2015): El principio de transparencia en el Estado Social de Derecho: una revisión de la legitimidad política (Cali, Editorial Bonaventuriana).

SÁNCHEZ, NELSON CAMILO E IBÁÑEZ GUTIÉRREZ, CATALINA (2014): "La justicia transicional como categoría constitucional", en: Ambos, Kai (Coordinador), Justicia de Transición y Constitución: análisis de la Sentencia C-579 de 2013 de la Corte Constitucional (Bogotá D.C., Editorial Temis), pp. 107-154.

SERNA, PEDRO (1989): "Modernidad, posmodernidad y derecho natural: un iusnaturalismo posible", en: Persona y Derecho: Revista de fundamentación de las instituciones jurídicas y de derechos humanos 
( $\left.\mathrm{N}^{\circ} 20\right), \quad$ pp. 155-188. Disponible http://dadun.unav.edu/bitstream/10171/12679/1/PD_20_04.pdf [visitado el 24 de enero de 2017]. SOFSKY, WOLFGANG (2004): Tiempos de horror: Amok, violencia, guerra (Madrid, Siglo XXI Editores). TAFUR CHARRY, MAGDA PAOLA (2016): Precedente jurisprudencial en materia de justicia transicional (Bogotá D.C., Universidad Católica de Colombia).

TEITEL, RUTI G. (2017): Justicia Transicional (Bogotá D.C.: Universidad Externado de Colombia).

TREVIÑO MORENO, PEDRO (2006): "Apuntes para una definición de la modernidad”, en: Zeraoui, Zidane (edit.), Modernidad y Posmodernidad: la crisis de los paradigmas y valores (México, Noriega Editores), pp. 9-25.

UPRIMNY, RODRIGO Y SAFFON, MARÍA PAULA (2006): "Justicia transicional y justicia restaurativa: tensiones y complementariedades", en: Uprimny, Rodrigo, Saffon, María Paula, Botero, Catalina y Restrepo, Esteban, ¿Justicia transicional sin transición? Verdad, justicia y reparación para Colombia (Bogotá D.C., De Justicia), pp. 109-138.

VASSALLI, GIULIANO (2014): Fórmula de Radbruch y derecho penal (Bogotá D.C., Temis).

VATTIMO, GIANNI (1994): “Posmodernidad: ¿una sociedad transparente?", en: Vattimo, Gianni et al., En torno a la posmodernidad (Bogotá D.C., Siglo del Hombre Editores), primera edición, primera reimpresión, pp. 9-19.

(1991): Ética de la interpretación (Barcelona, Paidós).

VIGO, RODOLFO LUIS (2015): lusnaturalismo y Neoconstitucionalismo: coincidencias y diferencias (Bogotá D.C.: Universidad Libre).

(2012): Constitucionalización y Judicialización del Derecho (Bogotá D.C.: Grupo Editorial Ibáñez, Pontificia Universidad Javeriana).

(2001): "Los principios jurídicos y su impacto en la teoría actual", en: Persona y Derecho: Revista de Fundamentación de las Instituciones Jurídicas y de Derechos Humanos ( $\left.N^{\circ} 44\right)$, pp. 65102. Disponible en: http://dadun.unav.edu/handle/10171/14175 [visitado el 18 de mayo de 2019].

ZAGREBELSKY, GUSTAVO (1995): El derecho dúctil (Madrid, Trotta).

ZERAOUI, ZIDANE (2006): "La crisis de los paradigmas: por una nueva lectura de la historia", en: Zeraoul, Zidane (edit.), Modernidad y Posmodernidad: la crisis de los paradigmas y valores. (México, Noriega Editores), pp. 27-49. 